\title{
Benchtop study of leakages across the Portex, TaperGuard, and Microcuff endotracheal tubes under simulated clinical conditions
}

\author{
Arthur CW Lau *, SM Lam, WW Yan
}

\section{A B S T R A C T}

Objectives: To compare three endotracheal tubes for leakage across the cuff (microaspiration) under a comprehensive set of simulated clinical situations. These were the Mallinckrodt TaperGuard (Covidien, US) with a tapered polyvinyl chloride cuff; the KimVent Microcuff (Kimberly-Clark Health Care, US) with a cylindrical polyurethane cuff; and a conventional Portex (Smiths Medical International Ltd, UK) with a globular polyvinyl chloride cuff.

Design: A benchtop experimental study.

Setting and materials: A silicone cylinder serving as the model trachea was intubated with each of the three endotracheal tubes, one at a time. A total of 20 $\mathrm{mL}$ of water were added above the cuff and leakage measured every minute for 20 minutes under five simulated mechanical ventilation scenarios, including different positive end-expiratory pressure levels, and disconnection with and without spontaneous breathing efforts. Each scenario was studied under three cuff pressures of 10,20 and $30 \mathrm{~cm} \mathrm{H}_{2} \mathrm{O}$, and then repeated with the application of a continuous suction force of $200 \mathrm{~cm} \mathrm{H}_{2} \mathrm{O}$, and leakage measured every minute for 3 minutes.

Results: The outcome of interest was the cumulative amount of leakage. The Microcuff endotracheal tubes with an ultrathin polyurethane cuff consistently provided the best protection against microaspiration under all simulated clinical situations, followed by TaperGuard with a tapered cuff, and lastly Portex with a globular polyvinyl chloride cuff. Clinical scenarios associated with the greatest leakage were mechanical ventilation with zero positive end-expiratory pressure, circuit disconnection with spontaneous breathing efforts, application of suction, and a low cuff pressure.

Conclusions: Microcuff endotracheal tubes outperformed TaperGuard and Portex endotracheal tubes in preventing microaspiration, which is one of the major mechanisms for ventilator-associated pneumonia.

\section{Hong Kong Med J 2014;20:7-15}

DOI: 10.12809/hkmj133930

\section{ACW Lau *, FHKAM (Medicine)}

SM Lam, FHKAM (Medicine)

WW Yan, FHKAM (Medicine)

Department of Intensive Care, Pamela Youde Nethersole Eastern Hospital, Chai Wan, Hong Kong

* Corresponding author: laucw3@ha.org.hk

New knowledge added by this study

- Microcuff endotracheal tubes (ETTs) with an ultrathin polyurethane cylindrical cuff provided the best protection against microaspiration under diverse situations.

- TaperGuard ETT with a tapered polyvinyl chloride (PVC) cuff provided protection against microaspiration in simulated at-risk situations, given that the cuff pressure was maintained at the recommended 20 to $30 \mathrm{~cm}^{\circ} \mathrm{H}_{2} \mathrm{O}$.

- The most widely used Portex ETT with a globular PVC cuff did not protect against microaspiration under these at-risk simulated situations, even at recommended cuff pressures of 20 to $30 \mathrm{~cm} \mathrm{H}_{2} \mathrm{O}$.

Implications for clinical practice or policy

- This study supports more widespread use of ETTs with an ultrathin polyurethane cuff (eg the Microcuff) to better prevent microaspiration, which is one of the major mechanisms of ventilator-associated pneumonia.

- Some scenarios appear more prone to microaspirations, eg zero positive end-expiratory pressure, total disconnection, and spontaneous breathing. The Microcuff ETT outperformed other ETTs, particularly in such scenarios.

\section{Introduction}

One of the major mechanisms of ventilatorassociated pneumonia (VAP) is microaspiration of bacteria-colonised oropharyngeal secretions that collect above the inflated cuff of the endotracheal tube (ETT). In Hong Kong, for several decades, the cuff of the most commonly used ETT has been made of polyvinyl chloride (PVC) and has a globular shape. This type of cuff protects against microaspiration poorly, due to microchannels formed from infolding of redundant cuff material after inflation. ${ }^{1}$ Novel designs of the ETT cuff attempt to overcome this problem by modifying the material from the thicker (50- to 80-micron) PVC to the ultrathin (10-micron) 


\section{模擬臨床環境下測試Portex 、TaperGuard和 Microcuff氣管內插管的滲漏情況 \\ 劉俊穎、林倩雯、殷榮華}

目的：在模擬臨床環境下測試以下兩種新的氣管內插管：有錐形聚 氯乙烯氣囊的Mallinckrodt TaperGuard（美國Covidien公司）以及 有圓柱形聚氨酯氣囊的KimVent Microcuff（美國Kimberly-Clark公 司）, 把它們與有球狀聚氯乙烯氣囊的Portex（英國Smiths Medical International Ltd）的傳統氣管內插管在氣囊處的滲漏情況（顯微吸 入現象) 進行比較。

設計：台式實驗研究。

安排和材料: 利用矽膠圓柱作模型氣管, 先後插入三款氣管內插管的 其中一枝。把 20 毫升的水倒入氣囊之上, 然後在五個模擬機械通氣的 情況下每分鐘記錄滲漏量, 整個過程維持 20 分鐘。測試中涉及不同呼 氣末正壓水平以及把呼吸機管路脱開（部份情況有自主呼吸），再分 別以 $10 、 20$ 和 $30 \mathrm{~cm} \mathrm{H} \mathrm{H}_{2} \mathrm{O}$ 三種氣囊壓力研究氣管內插管滲漏的情況。 然後加入 $200 \mathrm{~cm} \mathrm{H}$ O 的連續抽吸力重複測試, 每分鐘記錄滲漏量, 整個過程維持3分鐘。

結果：結果記錄了不同情況下的累積滲漏量。有超薄聚氨酯氣囊的 Microcuff氣管內插管在所有模擬情況下均能針對顯微吸入現象提供最 好的保護, 其次是有錐形氣囊的TaperGuard, 最後為有球狀聚氯乙烯 氣囊的Portex。最大滲漏量與下列臨床情況相關：呼氣末正壓為零的 機械式通氣、在有呼吸的情況下把呼吸機管路脱開、使用抽吸力和低 氣囊壓力。

結論：Microcuff氣管內插管在防止顯微吸入方面的表現比 TaperGuard和Portex優勝; 顯微吸入是呼吸機相關性肺炎的主要成因 之一。

\section{Methods}

The experimental setup is shown in Figure 1. The three types of ETTs under test were the Portex Endotracheal Tube (Smiths Medical International Ltd, UK) with a globular PVC cuff; the Mallinckrodt TaperGuard Endotracheal Tube (Covidien, US) with a tapered PVC cuff; and the KimVent Microcuff Endotracheal Tube (Kimberly-Clark Health Care, US) with a cylindrical PU cuff (Fig 2). A transparent, hollow silicone cylinder of length $20 \mathrm{~cm}$ and an internal diameter of $2 \mathrm{~cm}$ was used as the model trachea. An internal diameter of $2 \mathrm{~cm}$ was chosen because from autopsy studies, the mean diameters of male and female tracheas were $2.2 \mathrm{~cm}$ and 1.8 $\mathrm{cm}$, respectively. ${ }^{7}$ A flexible and extensible tube was added to the proximal end of the model trachea to prevent fluid from splashing out where significant upward leakage results from high positive ventilatory pressure. ${ }^{5}$ The ETT under study was connected to a SERVO-i Adult ventilator (Maquet $\mathrm{GmbH} \& \mathrm{Co}$. KG, Germany). The model trachea was inclined at 35 degrees to the horizontal to simulate the semirecumbent position for VAP prevention. Cuff pressure (Pcuff) was maintained by an automated maintenance setup as devised and modified from a previous study. ${ }^{8}$ In short, compressed air in the range of 2 to $3 \mathrm{~L} / \mathrm{min}$ was used to inflate the cuff and the pressure was altered with a leakage port along the circuit, to maintain the desired Pcuff within a range of $\pm 1 \mathrm{~cm} \mathrm{H} \mathrm{H}_{2} \mathrm{O}$ at end-expiration. The PVC cuff was monitored continuously using a calibrated electronic pressure transducer (Model HCLA0050EU; Sensortechnics GmbH, Germany), with signals digitally transformed by an analogue-to-digital converter (NI USB-6212; National Instruments, US), so as to display on a computer using the LabVIEW

polyurethane (PU), ${ }^{2}$ and the cuff shape from globular to tapered or cylindrical. In addition, a subglottic secretion drainage port for aspiration of secretions collected above the cuff is available in some ETTs. Although these novel ETTs have been available for many years, ${ }^{3,4}$ they are not widely used locally. Reasons include inadequate cost-effectiveness data, even though most studies reported favourable efficacy in reducing VAP, though not necessarily mortality. ${ }^{1}$

Many previous benchtop studies have shown the benefits of these novel designs, but mostly under a limited number of conditions, or under a static condition without the dynamic effect of different levels of positive pressures from mechanical ventilation or negative pressures associated with spontaneous breathing and/or suction. ${ }^{5,6}$ Moreover, they mostly reported the amount of leakage at a particular time point without showing continuous trends. ${ }^{5}$ The aim of the present study was to compare these novel ETTs under a comprehensive set of simulated clinical conditions, and to find the bestperforming tube in which downward leakage of fluid across the cuff was minimal.

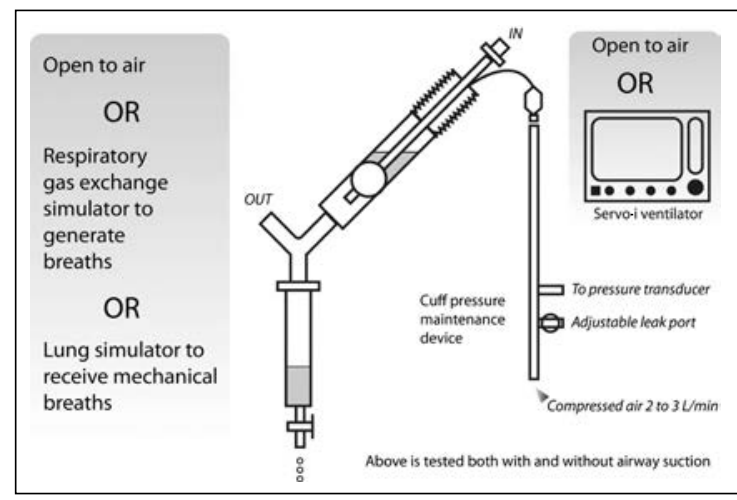

FIG I. Graphical representation of the experimental setup For the study of positive pressure mechanical ventilation, the distal end of the model trachea was connected to a lung simulator (SMS Lung Simulator, SMS Technologies, UK). For the study of spontaneous breathing, it was connected to a respiratory gas exchange simulator which generated breaths to mimic different metabolic rates. For the study of total disconnection, it was opened to atmospheric pressure 
2010 software (National Instruments Corporation, US). The proximal end of a Y-piece was connected to the distal end of the model trachea. To the Y-piece's vertical end, a water trap made of a $20-\mathrm{mL}$ syringe was connected. For the study of positive pressure mechanical ventilation, it was connected to a lung simulator (SMS Lung Simulator; SMS Technologies, UK) at its distal end. For the study of spontaneous breathing, it was connected to a Huszczuk-WhippWasserman Gas Exchange System Validator (MedGraphics, US) ${ }^{9}$ which generated breaths to mimic different metabolic rates; and for the study of total disconnection, it was opened to atmospheric pressure.

The scenarios simulated are shown in Table 1. Clear water $(20 \mathrm{~mL})$ was added above the ETT cuff. The whole process was recorded by a video recorder and leakage was measured as observed in the syringe for 20 minutes. Each scenario was studied under different Pcuffs of 10, 20, and $30 \mathrm{~cm} \mathrm{H}_{2} \mathrm{O}$. For each scenario at each Pcuff, two tubes of the same ETT type were tested, and each tube was studied repeatedly for 4 times, therefore making a total of 8 measurements for each ETT type per scenario and Pcuff.

The same scenarios were then repeated under sustained tracheal suction by placing a suction catheter (12-Fr closed suction catheter) inside the ETT near the Murphy eye,$^{10}$ and a suction pressure of $200 \mathrm{~cm} \mathrm{H}_{2} \mathrm{O}$ was applied continuously for 3 minutes.

The primary measurement was the downward leakage across the cuff, defined as the amount of fluid collected in the syringe (the fluid trap) every minute during the observation period.

\section{Statistical analysis}

Between- and within-group analysis of variance (ANOVA) was used for analysis of the amount of downward leakage during the whole observation period, with the aim of comparing the difference in leakage between the three types of ETTs for each scenario. Each scenario at each Pcuff was analysed separately, in which between-group data were different types of ETTs and within-group data were the cumulative amount (in $\mathrm{mL}$ ) of leakage over

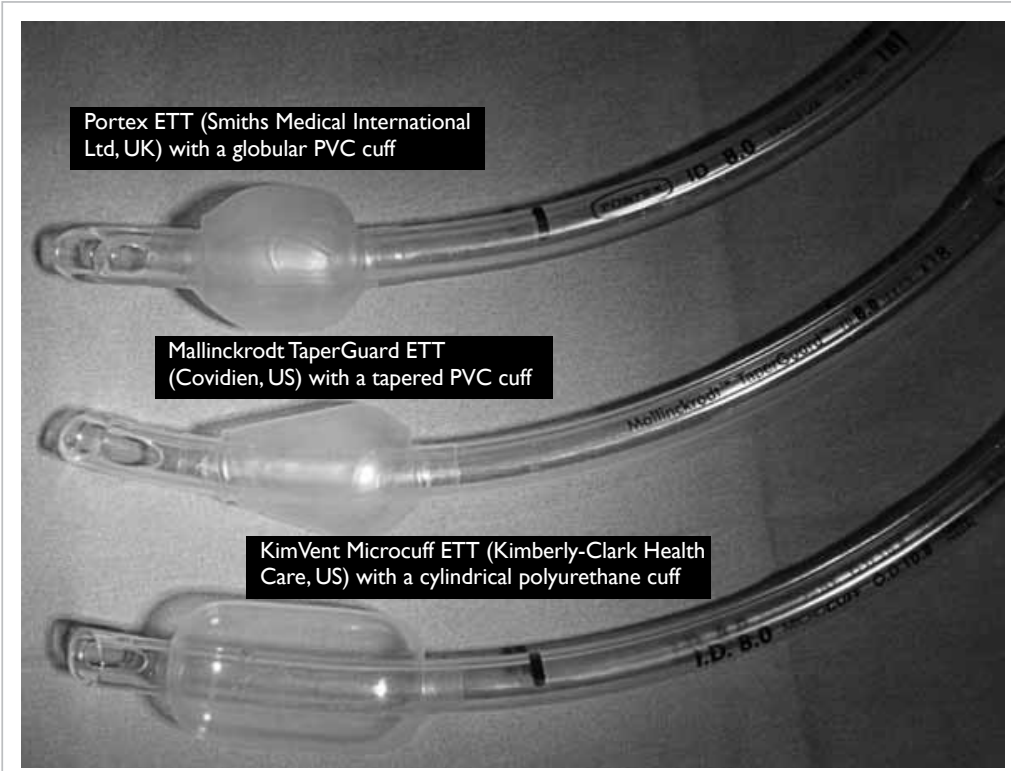

FIG 2. The three types of endotracheal tubes (ETTs) tested (8-mm internal diameter)

Abbreviation: PVC = polyvinyl chloride

TABLE I. Simulated clinical scenarios tested under three different cuff pressures $\left(10,20\right.$, and $\left.30 \mathrm{~cm} \mathrm{H}_{2} \mathrm{O}\right)$ using the three types of endotracheal tubes (ETTs) Each scenario at each cuff pressure was repeated 8 times for each type of ETT, making a total of $72(1 \times 3$ cuff pressures $\times 3$ ETT types $\times 2$ ETTs for each type $\times 4$ ) experiments per scenario. Suction was applied with a sustained pressure of $200 \mathrm{~cm} \mathrm{H}_{2} \mathrm{O}$ for 3 minutes at the Murphy eye

\begin{tabular}{|c|c|c|c|}
\hline \multicolumn{2}{|c|}{ Scenario } & \multirow[t]{2}{*}{ Simulated condition } & \multirow[t]{2}{*}{ Settings } \\
\hline Without suction & With suction & & \\
\hline $1 \mathrm{NS}$ & $1 S$ & Mechanical ventilation strategy for acute severe asthma & $\begin{array}{l}\mathrm{PEEP}=0 \mathrm{~cm} \mathrm{H}_{2} \mathrm{O} \\
\mathrm{PIP}=15 \mathrm{~cm} \mathrm{H} \mathrm{H}_{2} \\
\text { Frequency }=10 / \mathrm{min} \\
\mathrm{I}: \mathrm{E}=1: 5 \\
\text { Breath cycle }=4 \mathrm{sec}\end{array}$ \\
\hline 2NS & $2 S$ & Mechanical ventilation strategy for normal lungs & $\begin{array}{l}\text { PEEP }=5 \mathrm{~cm} \mathrm{H}_{2} \mathrm{O} \\
\text { PIP }=15 \mathrm{~cm} \mathrm{H}_{2} \mathrm{O} \text { on top of PEEP (ie } 20 \mathrm{~cm} \mathrm{H}_{2} \mathrm{O} \text { ) } \\
\text { Frequency }=15 / \mathrm{min} \\
\mathrm{l}: \mathrm{E}=1: 2.9 \\
\text { Breath cycle }=4 \mathrm{sec}\end{array}$ \\
\hline 3NS & $3 S$ & $\begin{array}{l}\text { Mechanical ventilation strategy for acute respiratory } \\
\text { distress syndrome }\end{array}$ & $\begin{array}{l}\text { PEEP }=10 \mathrm{~cm} \mathrm{H}_{2} \mathrm{O} \\
\text { PIP }=20 \mathrm{~cm} \mathrm{H}_{2} \mathrm{O} \text { on top of PEEP (ie } 30 \mathrm{~cm} \mathrm{H}_{2} \mathrm{O} \text { ) } \\
\text { Frequency }=20 / \mathrm{min} \\
\text { I:E }=1: 1 \\
\text { Breath cycle }=3 \mathrm{sec}\end{array}$ \\
\hline 4NS & $4 S$ & $\begin{array}{l}\text { Disconnection from ventilator with no spontaneous } \\
\text { breathing effort }\end{array}$ & $\begin{array}{l}\text { Distal end of Y-piece opened to atmospheric } \\
\text { pressure }\end{array}$ \\
\hline $5 \mathrm{NS}$ & $5 S$ & $\begin{array}{l}\text { Disconnection from ventilator with spontaneous breathing } \\
\text { generated from the Gas Exchange System Validator }\end{array}$ & $\begin{array}{l}\text { Frequency }=20 / \mathrm{min} \\
\text { Tidal volume }=1500 \mathrm{~mL} / \mathrm{breath}\end{array}$ \\
\hline
\end{tabular}

Abbreviations: PEEP = positive end-expiratory pressure; PIP = peak inspiratory pressure; l:E = inspiratory-to-expiratory ratio 

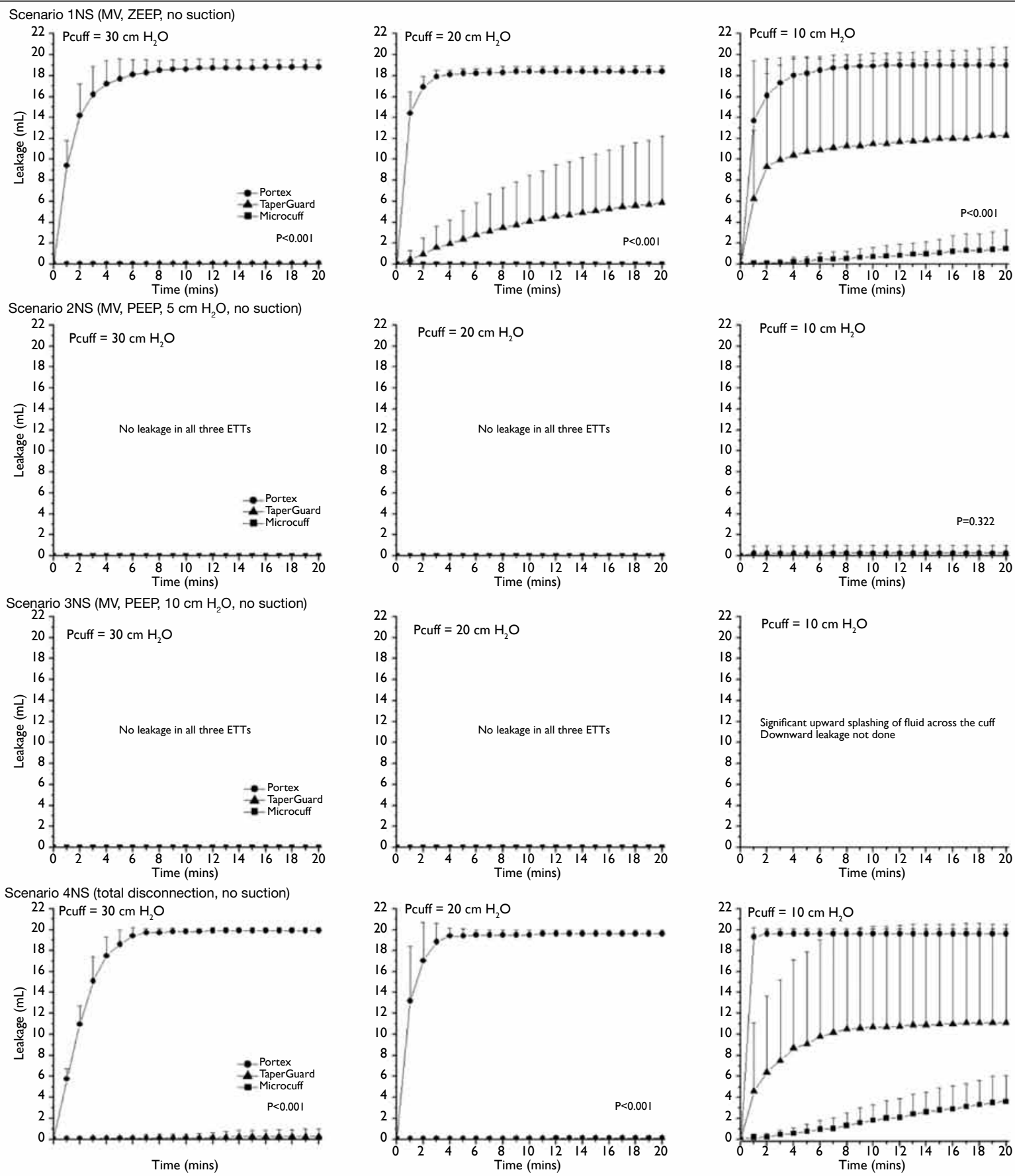

Scenario 5NS (spontaneous breathing, no suction)
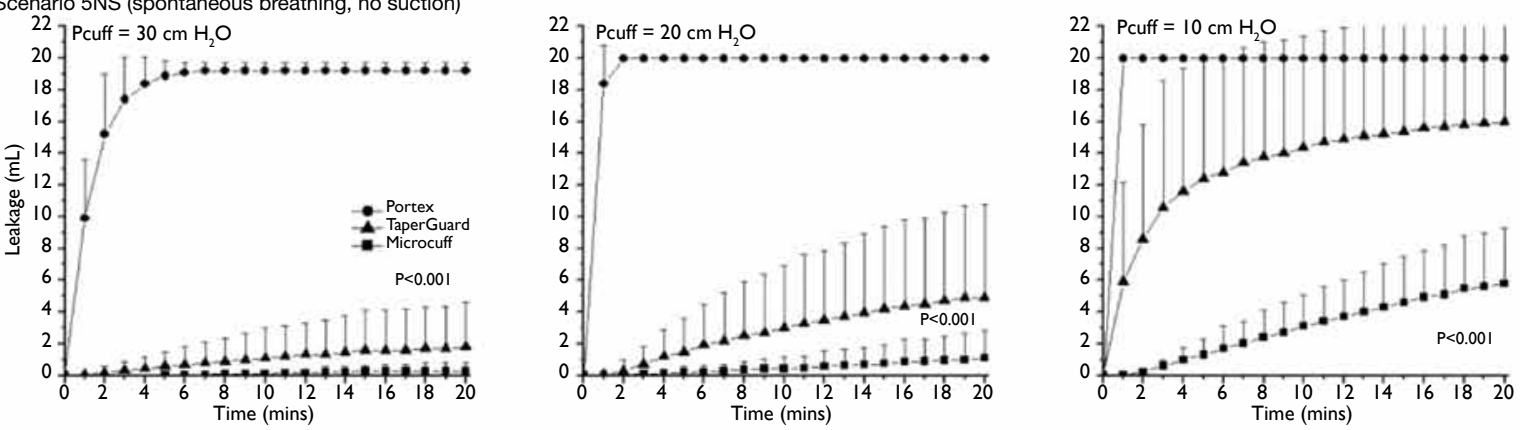

FIG 3. Downward leakage in the model trachea in the five scenarios without suction (INS to $5 N S$ )

Abbreviations: Pcuff = cuff pressure; MV = mechanical ventilation; ZEEP = zero end-expiratory pressure; PEEP = positive end-expiratory pressure; $E T T$ endotracheal tube

Circles denote Portex, triangles TaperGuard, and squares Microcuff. Each point represents the mean and the vertical bars the standard deviations of eight samples of repeated measures ( 2 endotracheal tubes $\times 4$ ). P values were obtained by analysis of variance over the whole 20-minute observation period 
each observation period. Statistical analysis was performed using IBM SPSS software version 20 (SPSS, Inc, IBM, US).

\section{Results}

Results of the five scenarios without suction (1NS to $5 \mathrm{NS}$ ) are shown in Figure 3. The P values represent analyses by ANOVA of the cumulative leakage over the whole 20-minute observation period. The cumulative leakages at the 20-minute time point are shown in Table 2. In summary, in scenario 1NS (positive end-expiratory pressure $[\mathrm{PEEP}]$ of $0 \mathrm{~cm}$
$\mathrm{H}_{2} \mathrm{O}$ ), the Microcuff outperformed the other two ETTs at all Pcuffs. At a Pcuff of $30 \mathrm{~cm} \mathrm{H}_{2} \mathrm{O}$, only the Portex showed leakage, which was early and massive. At a Pcuff of $20 \mathrm{~cm} \mathrm{H}_{2} \mathrm{O}$, only Microcuff did not leak. At a Pcuff of $10 \mathrm{~cm} \mathrm{H}_{2} \mathrm{O}$, all three ETTs leaked, but the rate was fastest in Portex and lowest in Microcuff. In scenario 2NS (PEEP of $5 \mathrm{~cm} \mathrm{H}_{2} \mathrm{O}$ ), at Pcuffs of 30 and $20 \mathrm{~cm} \mathrm{H} \mathrm{H}_{2} \mathrm{O}$, all three ETTs showed no leakage, while at a Pcuff of $10 \mathrm{~cm} \mathrm{H}_{2} \mathrm{O}$, only Portex showed minimal leakage. In scenario 3NS (PEEP of $10 \mathrm{~cm} \mathrm{H}_{2} \mathrm{O}$ ), none leaked. In scenario 4NS (disconnection), significant leakage occurred only in Portex at Pcuffs of 30 and $20 \mathrm{~cm} \mathrm{H}_{2} \mathrm{O}$. At a Pcuff of $10 \mathrm{~cm} \mathrm{H}_{2} \mathrm{O}$, all leaked, but

TABLE 2. Cumulative leakage at the 20-minute time point for different scenarios

\begin{tabular}{|c|c|c|c|c|c|c|}
\hline \multirow[t]{2}{*}{ Scenario } & \multirow{2}{*}{$\begin{array}{c}\text { PEEP } \\
\left(\mathrm{cm} \mathrm{H} \mathrm{H}_{2} \mathrm{O}\right)\end{array}$} & \multirow{2}{*}{$\begin{array}{c}\text { Pcuff } \\
\left(\mathrm{cm} \mathrm{H} \mathrm{H}_{2} \mathrm{O}\right)\end{array}$} & \multicolumn{4}{|c|}{ Observation / mean \pm standard deviation leakage $(\mathrm{mL})$} \\
\hline & & & Without suction (NS) & $P$ value & With suction (S) & $P$ value \\
\hline \multirow[t]{3}{*}{1} & 0 & 30 & $\begin{array}{c}\text { PT: } 18.8 \pm 0.7 \\
\text { TG: } 0.0 \pm 0.1 \\
\text { MC: } 0.0 \pm 0.7\end{array}$ & $<0.001$ & $\begin{array}{l}\text { PT: } 19.7 \pm 0.4 \\
\text { TG: } 12.0 \pm 6.2 \\
\text { MC: } 0.0 \pm 0.0\end{array}$ & $<0.001$ \\
\hline & & 20 & $\begin{array}{c}\text { PT: } 18.4 \pm 0.5 \\
\text { TG: } 5.9 \pm 6.3 \\
\text { MC: } 0.0 \pm 0.0\end{array}$ & $<0.001$ & $\begin{array}{l}\text { PT: } 20.0 \pm 0.1 \\
\text { TG: } 11.1 \pm 6.9 \\
\text { MC: } 0.1 \pm 0.2\end{array}$ & $<0.001$ \\
\hline & & 10 & $\begin{array}{l}\text { PT: } 19.0 \pm 0.5 \\
\text { TG: } 12.3 \pm 8.4 \\
\text { MC: } 1.5 \pm 1.8\end{array}$ & $<0.001$ & $\begin{array}{l}\text { PT: } 20.0 \pm 0.0 \\
\text { TG: } 17.0 \pm 3.9 \\
\text { MC: } 1.8 \pm 0.8\end{array}$ & $<0.001$ \\
\hline \multirow[t]{3}{*}{2} & 5 & 30 & No leakage for all three types & - & $\begin{array}{c}\text { PT: } 19.7 \pm 0.4 \\
\text { TG: } 0.0 \pm 0.1 \\
\text { MC: } 0.0 \pm 0.0\end{array}$ & $<0.001$ \\
\hline & & 20 & No leakage for all three types & - & $\begin{array}{l}\text { PT: } 19.9 \pm 0.4 \\
\text { TG: } 7.4 \pm 6.2 \\
\text { MC: } 0.0 \pm 0.0\end{array}$ & $<0.001$ \\
\hline & & 10 & $\begin{array}{l}\text { PT: } 0.3 \pm 0.7 \\
\text { TG: } 0.0 \pm 0.0 \\
\text { MC: } 0.0 \pm 0.0\end{array}$ & 0.322 & $\begin{array}{l}\text { PT: } 20.0 \pm 0.0 \\
\text { TG: } 12.7 \pm 5.1 \\
\text { MC: } 0.9 \pm 0.8\end{array}$ & $<0.001$ \\
\hline \multirow[t]{3}{*}{3} & 10 & 30 & No leakage for all three types & - & No leakage for all three types & - \\
\hline & & 20 & No leakage for all three types & - & $\begin{array}{l}\text { PT: } 0.6 \pm 1.1 \\
\text { TG: } 0.0 \pm 0.0 \\
\text { MC: } 0.0 \pm 0.0\end{array}$ & 0.405 \\
\hline & & 10 & No leakage for all three types & - & Not done* & - \\
\hline \multirow[t]{3}{*}{4} & Disconnection & 30 & $\begin{array}{c}\text { PT: } 19.9 \pm 0.3 \\
\text { TG: } 0.3 \pm 0.7 \\
\text { MC: } 0.0 \pm 0.1\end{array}$ & $<0.001$ & $\begin{array}{c}\text { PT: } 20.0 \pm 0.0 \\
\text { TG: } 0.2 \pm 0.4 \\
\text { MC: } 0.1 \pm 0.1\end{array}$ & $<0.001$ \\
\hline & & 20 & $\begin{array}{c}\text { PT: } 19.6 \pm 0.4 \\
\text { TG: } 0.1 \pm 0.1 \\
\text { MC: } 0.1 \pm 0.2\end{array}$ & $<0.001$ & $\begin{array}{c}\text { PT: } 20.0 \pm 0.0 \\
\text { TG: } 2.4 \pm 2.4 \\
\text { MC: } 0.0 \pm 0.1\end{array}$ & $<0.001$ \\
\hline & & 10 & $\begin{array}{l}\text { PT: } 19.6 \pm 0.5 \\
\text { TG: } 11.1 \pm 9.4 \\
\text { MC: } 3.6 \pm 2.5\end{array}$ & $<0.001$ & $\begin{array}{l}\text { PT: } 19.9 \pm 0.4 \\
\text { TG: } 13.9 \pm 5.9 \\
\text { MC: } 0.3 \pm 0.4\end{array}$ & $<0.001$ \\
\hline \multirow[t]{3}{*}{5} & $\begin{array}{l}\text { Spontaneous } \\
\text { breathing }\end{array}$ & 30 & $\begin{array}{l}\text { PT: } 19.2 \pm 0.5 \\
\text { TG: } 1.8 \pm 2.8 \\
\text { MC: } 0.3 \pm 0.5\end{array}$ & $<0.001$ & $\begin{array}{l}\text { PT: } 20.0 \pm 0.0 \\
\text { TG: } 0.0 \pm 0.0 \\
\text { MC: } 0.1 \pm 0.1\end{array}$ & $<0.001$ \\
\hline & & 20 & $\begin{array}{l}\text { PT: } 20.0 \pm 0.0 \\
\text { TG: } 4.9 \pm 5.9 \\
\text { MC: } 1.1 \pm 1.7\end{array}$ & $<0.001$ & $\begin{array}{l}\text { PT: } 20.0 \pm 0.0 \\
\text { TG: } 1.0 \pm 1.9 \\
\text { MC: } 0.0 \pm 0.0\end{array}$ & $<0.001$ \\
\hline & & 10 & $\begin{array}{l}\text { PT: } 20.0 \pm 0.0 \\
\text { TG: } 16.0 \pm 6.7 \\
\text { MC: } 5.8 \pm 3.5\end{array}$ & $<0.001$ & $\begin{array}{l}\text { PT: } 20.0 \pm 0.0 \\
\text { TG: } 20.0 \pm 0.0 \\
\text { MC: } 12.5 \pm 4.3\end{array}$ & $<0.001$ \\
\hline
\end{tabular}

Abbreviations: PEEP = positive end-expiratory pressure; Pcuff = cuff pressure; PT = Portex; TG = TaperGuard; MC = Microcuff

* Significant upward splashing of fluid across the cuff; downward leakage not done 
the rate was lowest with Microcuff. In scenario 5NS (spontaneous breathing), addition of spontaneous breathing led to leakage in all ETTs at Pcuffs of 10 and $20 \mathrm{~cm} \mathrm{H}_{2} \mathrm{O}$, but the rate remained the lowest in Microcuff. At a Pcuff of $30 \mathrm{~cm} \mathrm{H}_{2} \mathrm{O}$, only Microcuff showed minimal leakage.

Results of the five scenarios with suction (1S to $5 \mathrm{~S}$ ) are shown in Figure 4. The P values pertained to analyses by ANOVA of the whole 3-minute observation period. The cumulative leakages at the $3-$ minute time point are shown in Table 2. In summary, in scenario $1 \mathrm{~S}$ (PEEP of $0 \mathrm{~cm} \mathrm{H}_{2} \mathrm{O}$ ), at Pcuffs of 30 and $20 \mathrm{~cm} \mathrm{H}_{2} \mathrm{O}$, only Microcuff was protective, while the other two leaked almost instantly. At a Pcuff of $10 \mathrm{~cm} \mathrm{H}_{2} \mathrm{O}$, all three ETTs leaked, but Microcuff leaked very slowly. In scenario $2 S$ (PEEP of $5 \mathrm{~cm}$ $\mathrm{H}_{2} \mathrm{O}$ ), at a Pcuff of $30 \mathrm{~cm} \mathrm{H}_{2} \mathrm{O}$, leakage occurred instantly with Portex, in contrast to zero leakage in the corresponding scenario without suction. At a Pcuff of $20 \mathrm{~cm} \mathrm{H} \mathrm{H}_{2} \mathrm{O}$, only Microcuff did not leak. At a Pcuff of $10 \mathrm{~cm} \mathrm{H}_{2} \mathrm{O}$, all three ETTs leaked, but Microcuff leaked very slowly. In scenario 3S (PEEP of $10 \mathrm{~cm} \mathrm{H} \mathrm{H}_{2} \mathrm{O}$ ), at a Pcuff of $30 \mathrm{~cm} \mathrm{H}_{2} \mathrm{O}$, none leaked. At a Pcuff of $20 \mathrm{~cm} \mathrm{H}_{2} \mathrm{O}$, minimal leakage occurred with Portex. In scenario $4 \mathrm{~S}$ (disconnection), at a Pcuff of $30 \mathrm{~cm} \mathrm{H}_{2} \mathrm{O}$, significant leakage was found in Portex. At a Pcuff of $20 \mathrm{~cm} \mathrm{H} \mathrm{H}_{2} \mathrm{O}$, only Microcuff was protective whilst TaperGuard leaked slowly. At a Pcuff of $10 \mathrm{~cm} \mathrm{H}_{2} \mathrm{O}$, Microcuff was still protective with minimal leakage at 3 minutes. In scenario $5 \mathrm{~S}$ (spontaneous breathing), at a Pcuff of $30 \mathrm{~cm} \mathrm{H}_{2} \mathrm{O}$, significant leakage was found in Portex. At a Pcuff of $20 \mathrm{~cm} \mathrm{H}_{2} \mathrm{O}$, Portex leaked significantly, TaperGuard leaked very slowly, while Microcuff was protective. At a Pcuff of $10 \mathrm{~cm} \mathrm{H}_{2} \mathrm{O}$, all three leaked.

\section{Discussion}

The present benchtop study showed that under the various simulated scenarios studied (positive pressure ventilation, disconnection, spontaneous breathing, with or without the application of suction), the Microcuff ETT consistently outperformed the others with the least downward leak and the lowest sealing pressure, whereas the TaperGuard ETT was in second place. The Portex ETT performed the worst, with significant leakage whenever there was a loss of positive airway pressure even at the recommended Pcuffs of 20 to $30 \mathrm{~cm} \mathrm{H}_{2} \mathrm{O}$.

Among the limitations of the present study, many in-vivo factors were not or could not be fully simulated but might have affected the leakage rate. In-vivo leakage could be greater when there is a change in tracheal dimensions during inspiration and/or imperfect conformation of the circular cuff to the trachea (which could have different anteroposterior compared with transverse dimensions), and when there is a sudden change in airway pressure or the cuff position inside the trachea as the patient coughs or moves. Moreover, the seal between the cuff and the moist tracheal mucosa might actually be better, especially with the use of lubricant at the time of intubation. ${ }^{4,11,12}$ The upward sweeping movement of the ciliated mucosa might also decrease aspiration. Furthermore, subglottic collections are more viscous than water, and their volume is not likely to be as high as $20 \mathrm{~mL}$. This volume was chosen in the current experiment to better discriminate ETT performance and minimise measurement errors. Dynamic patient factors may also affect leakage. For example, leakage in the first scenario (zero PEEP) might be less if significant auto-PEEP develops in severe airflow obstruction, and the size of the cuff relative to the trachea might increase or decrease leakage. Nor did we test the effect of subglottic suction, which is extremely effective in removing fluid collected above the cuff. However, the effectiveness of subglottic suction might differ in vivo, depending on the viscosity of secretions and apposition of the posterior mucosal wall obstructing the suction lumen and interfering with such efforts. ${ }^{13}$ According to guidelines on endotracheal suction for adults, ${ }^{14}$ the lowest suction pressure that can effectively clear secretions should be used, which should not exceed $150 \mathrm{~cm} \mathrm{H} \mathrm{H}_{2} \mathrm{O}$, and for not more than 15 seconds. We deliberately used sustained suction at $200 \mathrm{~cm} \mathrm{H}_{2} \mathrm{O}$ for 3 minutes to better discriminate the performance of each ETT. Notably though, in the present experiment it was observed that leakage occurred within the first second of suction. Although it can be argued that a 20 -minute observation period may be too short, we found that prolonging this period led to excessive evaporation of the water above the cuff. We did not use coloured water because we measured water collected in the syringe, simulating the volume of fluid actually aspirated into the lower airway, and not the minute amounts that might just leak and stay around the cuff. Fluid more viscous than water was not used because firstly, human secretions can never be fully simulated, and secondly, should there be any leakage, fluid of a lower viscosity (like water) was considered more liable to leak. Furthermore, the need for thorough cleansing of viscous fluid by dismantling the connections of the apparatus after each set of experiments was another consideration. Such cleansing was regarded as not feasible, because each connection needed to be secured with glue and tapes to withstand the high positive airway pressure and this would take an unrealistic amount of time to do so repeatedly.

The present experiment clearly discriminated the performance characteristics of the three ETTs. Infolding of the excess and thick PVC material in the Portex ETT formed micro-channels through which leakage occurred. By modifying the cuff to a tapered shape, leakage in the TaperGuard ETT was 
Scenario $1 \mathrm{~S}$ (MV, ZEEP, suction)

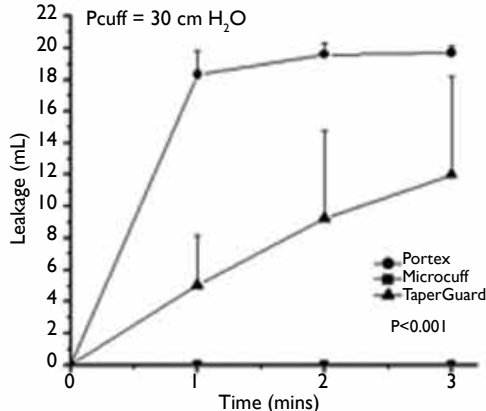

Scenario 2S (MV, PEEP, $5 \mathrm{~cm} \mathrm{H} \mathrm{H}_{2} \mathrm{O}$ suction)

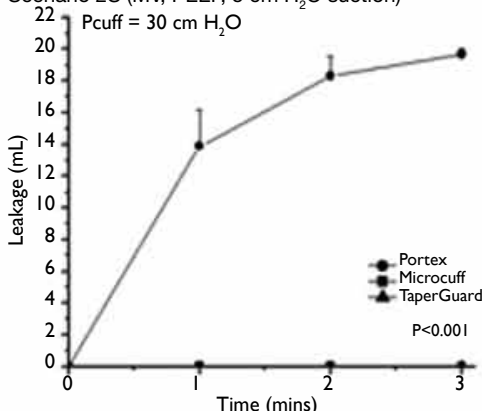

Scenario $3 \mathrm{~S}$ (MV, PEEP, $10 \mathrm{~cm} \mathrm{H}_{2} \mathrm{O}$, suction)

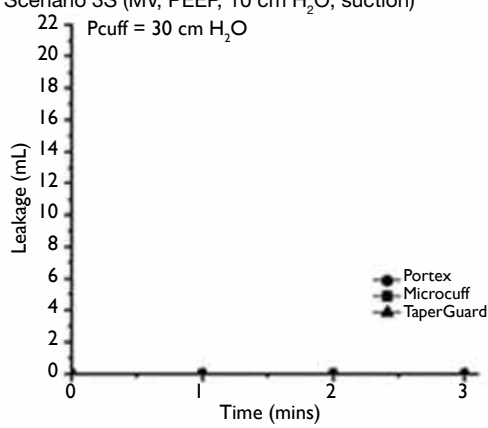

Scenario 4S (total disconnection, suction)

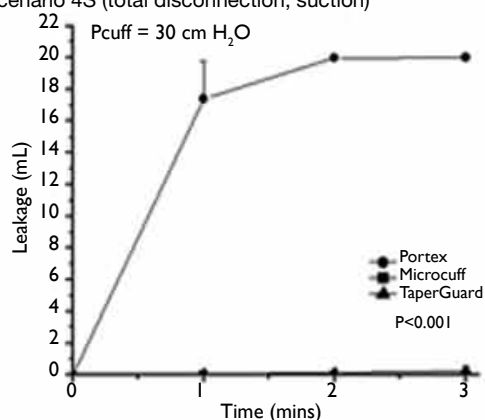

Scenario $5 \mathrm{~S}$ (spontaneous breathing, suction)

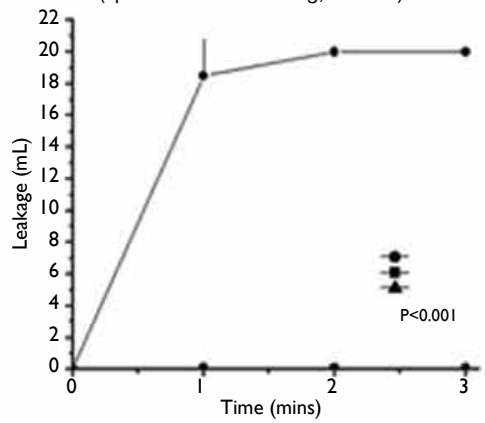

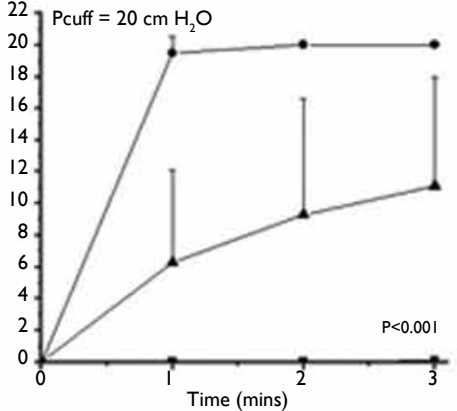
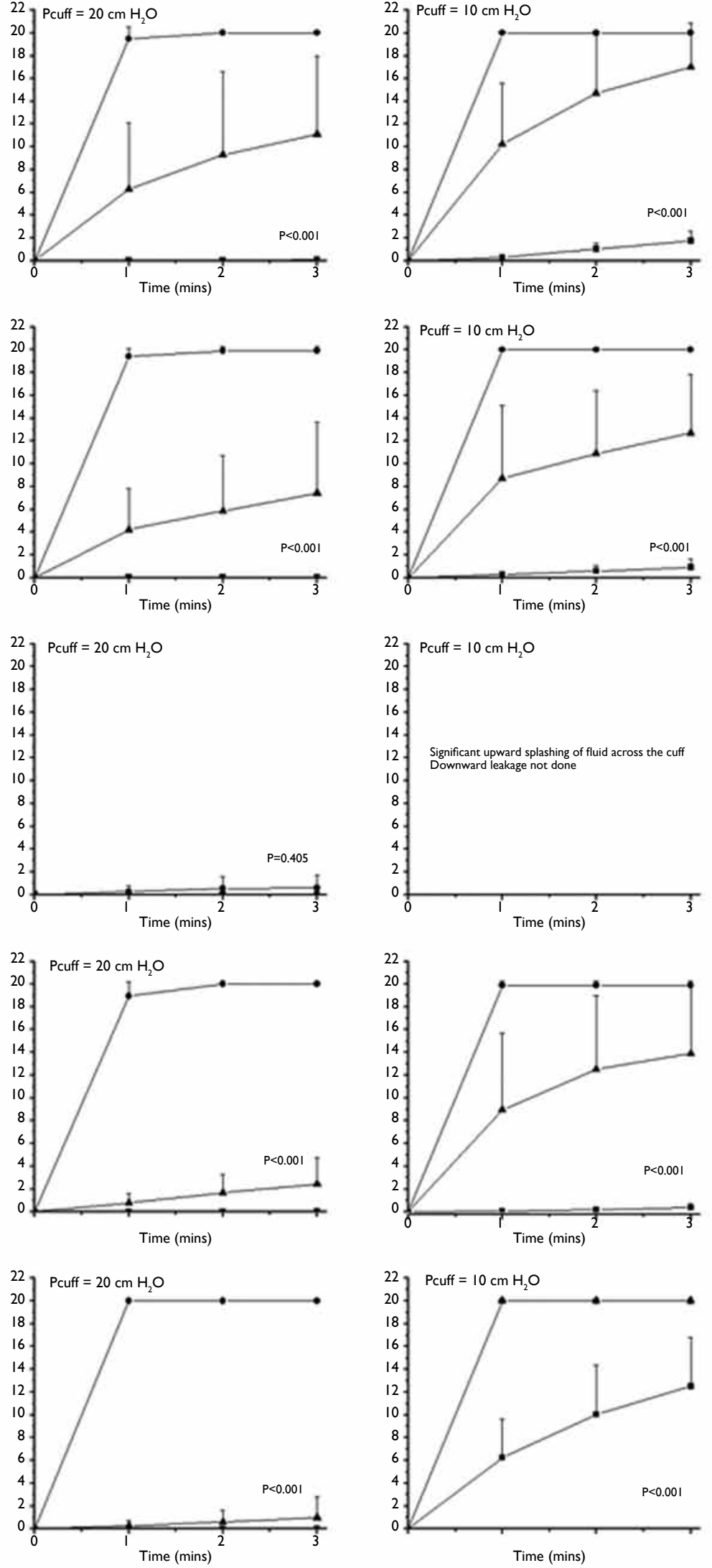

FIG 4. Downward leakage in the model trachea in the five scenarios after application of continuous suction of $200 \mathrm{~cm} H \mathrm{O}$ for $3 \mathrm{minutes}$ (IS to $5 \mathrm{~S}$ ) Abbreviations: Pcuff = cuff pressure; MV = mechanical ventilation; ZEEP = zero end-expiratory pressure; PEEP = positive end-expiratory pressure; ETT endotracheal tube

Circles denote Portex, triangles TaperGuard, and squares Microcuff. Each point represents the mean and the vertical bars the standard deviation of eight samples of repeated measures ( 2 endotracheal tubes $\times 4)$. $P$ values were obtained by analysis of variance of the whole 3 -minute observation period 
minimised, as there was a point along the length of the cuff where it fitted the trachea perfectly without the infolding of excess cuff material. In the Microcuff ETT, infolding of excess cuff material was still observed. However, micro-channels were not formed because of the much thinner PU material. Its cylindrical shape also provided a larger contact area between the cuff and tracheal wall, thus providing a better seal than the other two types of ETTs.

One of the clinical implications of our findings was that PEEP guards against downward leakage across cuffs, irrespective of the ETT type and Pcuff. In a previous study, it was shown that only the application of a $35 \mathrm{~cm} \mathrm{H}_{2} \mathrm{O}$ PEEP prior to cuff deflation at extubation was protective against aspiration, but not open or closed suction (that supposedly removes aspirated water). ${ }^{15}$ This protective effect of a higher PEEP was independent of the peak inspiratory pressure (PIP) as leakage still occurred in scenario 1NS (with a PIP of $15 \mathrm{~cm} \mathrm{H}_{2} \mathrm{O}$ ); such finding was in line with another study showing that only higher PEEP values and not higher inspiratory pressures were protective. ${ }^{16}$ However, the protective effect of PEEP, especially with low pressures of around $5 \mathrm{~cm}$ of $\mathrm{H}_{2} \mathrm{O}$, was counteracted by the application of suction, as shown by the appearance of leakage when suction was applied to the Portex and TaperGuard ETTs as in scenario $2 \mathrm{~S}$. Another study showed that when suction at 200 or 300 mbar was applied via ETTs with a PVC cuff, leakage could only be reduced by transiently increasing Pcuff to $50 \mathrm{~cm} \mathrm{H}_{2} \mathrm{O}$, and not at all by increasing the PEEP from 5 to $10 \mathrm{~cm} \mathrm{H}_{2} \mathrm{O}$ or the PIP from 15 to $25 \mathrm{~cm} \mathrm{H}_{2} \mathrm{O}^{17}$ This same study also showed that the PU cuff almost eliminated leakage under all suction pressures, and all PEEP or PIP values. ${ }^{17}$ Therefore, to prevent leakage during suction, a Pcuff of $50 \mathrm{~cm} \mathrm{H}_{2} \mathrm{O}$ may be necessary unless a PU cuff is used, while the suction duration and force should be reduced to a minimum, and routine suction should always be avoided. Given that suctioning results in the loss of PEEP and recruitment manoeuvres are recommended thereafter, ${ }^{14}$ it may be worth studying whether the application of high PEEP during suction can prevent both derecruitment and leakage across the cuff.

Similar to the effect of applying no PEEP during mechanical ventilation, disconnection from such ventilation results in significant leakage across the cuff, and should be avoided as far as possible. Harnessing the portability of an intensive care unit ventilator to avoid circuit disconnections should therefore be considered when patients are transported. When disconnection is necessary, its duration should be kept to a minimum with the maintenance of PEEP. For example, a PEEP valve from a bag-valve device may minimise leakage across the cuff. Spontaneous breathing during disconnection, which creates a negative intrathoracic pressure, further exacerbates downward leakage (scenario 5NS). Another study has also found that leakage increased with increasing inspiratory effort. ${ }^{16}$ Therefore, during disconnection for spontaneous breathing trials, microaspiration is to be expected if the conventional globular PVC cuff is used. Even with the use of novel ETTs, a high patient inspiratory effort during a trial of spontaneous breathing is conducive to microaspiration and should be anticipated. Extrapolating these results, a high patient inspiratory effort while on mechanical ventilation may prove to be another scenario at high risk of microaspiration.

Under situations with a high risk of microaspiration, namely zero or low PEEP, circuit disconnection, in the presence of high patient inspiratory effort and application of a suction force, the type of ETT used will make a difference to the rate of downward leakage. The Microcuff ETT was shown to offer the best protection in these situations. The TaperGuard ETT was protective if a higher Pcuff could be maintained, and a Pcuff maintenance device (keeping it between 20 and $30 \mathrm{~cm}$ of $\mathrm{H}_{2} \mathrm{O}$ ) may be helpful. Notably, the most commonly used Portex ETT provided the least protection against microaspiration, and leakage occurred in these situations despite maintaining a Pcuff at the recommended 20 to $30 \mathrm{~cm} \mathrm{H}_{2} \mathrm{O}$.

Based on the findings of the present study, further clinical trials on VAP prevention using novel ETTs less prone to microaspiration are needed. These should control for confounding factors including PEEP, airway suction, use of automated Pcuff maintenance devices, and airway disconnections. At the time of writing, the cost of a Microcuff ETT was around 6 times that of a Portex ETT (HK\$68 vs HK\$11), and a TaperGuard ETT was around double (HK\$20). Although cost-effectiveness analysis is worthwhile as a basis for wider promotion of the novel ETTs, taking into account the small absolute cost difference, there may be a case for just switching ETTs to those with a lesser tendency to leak until evidence to the contrary appears.

\section{Conclusions}

The present benchtop study showed that a higher PEEP, avoidance of unnecessary circuit disconnections and suctioning, and maintenance of adequate Pcuff are important in minimising microaspiration. The Microcuff ETT was shown to be superior to TaperGuard and Portex ETTs in preventing leakage across the cuff. As microaspiration is one of the major mechanisms of VAP, more widespread use of ETTs with a PU cuff, combined with other prevention measures (eg bedhead elevation, oral hygiene) may help to reduce the frequency of associated pneumonias. 


\section{Declaration}

No conflicts of interest were declared by the authors.

\section{References}

1. Fernandez JF, Levine SM, Restrepo MI. Technologic advances in endotracheal tubes for prevention of ventilatorassociated pneumonia. Chest 2012;142:231-8.

2. Bulpa P, Bouhon S, Schryvers F, et al. Microaspirations during mechanical ventilation: polyurethane versus polyvinyl cuffed endotracheal tubes. Crit Care 2010;14(Suppl 1):228S.

3. Dullenkopf A, Gerber A, Weiss M. Fluid leakage past tracheal tube cuffs: evaluation of the new Microcuff endotracheal tube. Intensive Care Med 2003;29:184953.

4. Dullenkopf A, Schmitz A, Frei M, Gerber AC, Weiss M. Air leakage around endotracheal tube cuffs. Eur J Anaesthesiol 2004;21:448-53.

5. Pitts R, Fisher D, Sulemanji D, Kratohvil J, Jiang Y, Kacmarek R. Variables affecting leakage past endotracheal tube cuffs: a bench study. Intensive Care Med 2010;36:206673.

6. Zanella A, Scaravilli V, Isgrò S, et al. Fluid leakage across tracheal tube cuff, effect of different cuff material, shape, and positive expiratory pressure: a bench-top study. Intensive Care Med 2011;37:343-7.

7. Mehta S, Myat HM. The cross-sectional shape and circumference of the human trachea. Ann R Coll Surg Engl 1984;66:356-8.

8. Farré R, Rotger M, Ferre M, Torres A, Navajas D. Automatic regulation of the cuff pressure in endotracheally-intubated patients. Eur Respir J 2002;20:1010-3.
9. Huszczuk A, Whipp BJ, Wasserman K. A respiratory gas exchange simulator for routine calibrator in metabolic studies. Eur Respir J 1990;3:465-8.

10. Dave MH, Frotzler A, Madjdpour C, Koepfer N, Weiss M. Massive aspiration past the tracheal tube cuff caused by closed tracheal suction system. J Intensive Care Med 2011 Feb 7. Epub ahead of print.

11. Dave MH, Koepfer N, Madjdpour C, Frotzler A, Weiss M. Tracheal fluid leakage in benchtop trials: comparison of static versus dynamic ventilation model with and without lubrication. J Anesth 2010;24:247-52.

12. Blunt MC, Young PJ, Patil A, Haddock A. Gel lubrication of the tracheal tube cuff reduces pulmonary aspiration. Anesthesiology 2001;95:377-81.

13. Dragoumanis CK, Vretzakis GI, Papaioannou VE, Didilis VN, Vogiatzaki TD, Pneumatikos IA. Investigating the failure to aspirate subglottic secretions with the Evac endotracheal tube. Anesth Analg 2007;105:1083-5.

14. American Association for Respiratory Care. AARC Clinical Practice Guidelines. Endotracheal suctioning of mechanically ventilated patients with artificial airways 2010. Respir Care 2010;55:758-64.

15. Hodd J, Doyle A, Carter J, Albarran J, Young P. Increasing positive end expiratory pressure at extubation reduces subglottic secretion aspiration in a bench-top model. Nurs Crit Care 2010;15:257-61.

16. Ouanes I, Lyazidi A, Danin PE, et al. Mechanical influences on fluid leakage past the tracheal tube cuff in a benchtop model. Intensive Care Med 2011;37:695-700.

17. Dave MH, Frotzler A, Weiss M. Closed tracheal suction and fluid aspiration past the tracheal tube. Impact of tube cuff and airway pressure. Minerva Anestesiol 2011;77:16671. 